\title{
INFLUÊNCIA DO CALENDÁRIO ELEITORAL SOBRE O MERCADO BRASILEIRO DE AÇÕES
}

\author{
INFLUENCE OF THE ELECTORAL CALENDAR ON THE \\ BRAZILIAN SHARE MARKET
}

\author{
Ari Araújo Junior ${ }^{1}$ \\ Leandro Nunes Moreira ${ }^{1}$ \\ Eduardo Senra Coutinho ${ }^{1}$ \\ Cláudio D. Shikida ${ }^{2}$
}

\section{Recebido em: 10/03/2016 Aceito em: 05/10/2016}

arifaj@gmail.com
Resumo: Este trabalho tem como objetivo testar a influência do calendário eleitoral (ciclos políticos) sobre o mercado brasileiro de ações. As variáveis dependentes são o risco e o retorno nominais e reais e os ativos selecionados foram lbovespa, Petr4 (Petrobrás) e Elet6 (Eletrobrás), em dados diários do período entre 1995 e 2010. O método utilizado foi o MQO com variáveis dummy - para captar os efeitos imediatos do calendário eleitoral e diferenças atribuíveis ao presidente no poder, e tendências de tempo - para captar variações ao longo dos mandatos. Os principais resultados são: durante o governo FHC os ativos em estudo apresentaram maior volatilidade que durante o governo Lula; os ativos das duas estatais são mais sensíveis às influências geradas pelas variáveis políticas dos modelos; o mercado reage ao resultado, ou provável resultado, das eleições de maneira imediata e não de forma gradativa ao longo dos mandatos. Os resultados indicam, de forma geral, que os ciclos políticos influenciam o risco e o retorno do mercado brasileiro de ações.

Palavras-chave: Ciclos Políticos. Calendário Eleitoral. Risco e Retorno.

Abstract: This study aims to test the influence of political cycles in the Brazilian stock market. The variables are returns (nominal and real) returns and risk (nominal and real) risk. Our selected assets were Ibovespa, PETR4 (Petrobrás) and Elet6 (Eletrobrás), with the daily data of the period between 1995 and 2010. The method used was OLS with dummy variables - (to capture the immediate effects of the electoral calendar and differences due to the president in power), and time trends - (to capture changes over presidential the terms). The main results are: higher volatility for the examined assets during the Cardoso administration than during the Lula administration; the assets of the two state owned enterprises (SOEs) are more susceptible to influences generated by the political variables of the models; markets reacts to the outcome, or likely outcome, elections immediately and not gradually over the mandates. In general, the results indicate that political cycles influence risk and returns in the Brazilian stock market.

Keywords: Political Cycles. Election Calendar. Risk and Return.

\footnotetext{
${ }^{1}$ Faculdade de Economia e Finanças IBMEC - IBMEC - Belo Horizonte - Minas Gerais - Brasil.

${ }^{2}$ Universidade Federal de Pelotas - UFPEL - Pelotas - Rio Grande do Sul - Brasil.
} 


\section{INTRODUÇÃO}

O mercado de ações é, geralmente, interpretado como um dos marcos do bom funcionamento de uma economia de mercado. A corrente principal em finanças indica que os mercados de capitais são eficientes, conforme a Hipótese da Eficiência de Mercado proposta por Fama (1971, pág. 384). Entretanto, do ponto de vista prático, pode-se relaxar a hipótese de que o mercado de ações funcione de maneira perfeita ou, ainda, procurar identificar anomalias mediante testes empíricos.

Entre as anomalias, pode-se que esperar que o mercado de ações não funcione eficientemente, por exemplo, por conta da intervenção governamental. Embora esta seja uma hipótese plausível, é necessário que se tenha alguma explicação para esta intervenção. Neste artigo, supõe-se que a mesma não se dá por qualquer motivo normativo como o de corrigir externalidades ou fornecer bens públicos, por exemplo. Admite-se a hipótese de que o mercado de ações seja influenciado por motivos compatíveis com a visão de que políticos respondem a incentivos. Em outras palavras, supõe-se que podem existir ciclos político-econômicos no mercado de ações.

Este artigo tem como objetivo testar a influência do calendário eleitoral sobre o mercado brasileiro de ações. As variáveis dependentes são o risco e o retorno nominais e reais e os ativos selecionados foram Ibovespa, Petr4 (Petrobrás) e Elet6 (Eletrobrás), em dados diários do período entre 1995 e 2010. Este trabalho, assim, busca evidências destes ciclos a partir da comparação do comportamento dos retornos e da volatilidade entre ações de empresas controladas pelo governo e a carteira representativa do mercado. A próxima seção faz uma breve apresentação das teorias dos ciclos econômicos politicamente induzidos. A metodologia e a base de dados são apresentadas na seção seguinte. Os resultados e conclusões compõem as últimas duas seções do artigo. Os resultados indicam, de forma geral, que os ciclos políticos influenciam o risco e o retorno do mercado brasileiro de ações.

\section{CICLOS POLÍTICOS E MERCADOS DE CAPITAIS}

A literatura sobre ciclos político-econômicos, iniciada nos anos 50, atualmente é uma das agendas de pesquisa mais bem estabelecidas na Economia conforme pode ser visto em Snowdon \& Vane (2005, pág. 517) ou Drazen (2000, pág. 228). Entretanto, não existem muitos estudos sobre ciclos deste tipo no mercado de ações. Fialho (1999) organiza a Teoria dos Ciclos Políticos em três enfoques: Modelos Clássicos, Partidários e Racionais.

Os modelos Clássicos que tiveram início com Downs (1957) e Nordhaus (1975) sugerem que os políticos comportam-se de maneira análoga aos empresários, sendo maximizadores do seu próprio bem-estar - dado pelo aumento dos votos e a permanência no poder (reeleição) - antes de qualquer outro objetivo. A ideia é que manipulações na curva de Philips de curto prazo, que implicam no trade-off entre inflação e desemprego, podem influenciar os resultados das eleições. Ou seja, o governo age de maneira oportunista no período pré-eleitoral criando um cenário econômico favorável 
através do estímulo à demanda agregada e redução no desemprego, mesmo que isso cause uma pequena inflação.

Os modelos Partidários também são baseados no trade-off inflação-desemprego, no entanto, tomam como decisivas as ideologias e metas dos partidos políticos. Partidos de esquerda (progressistas, socialistas) são mais avessos ao desemprego e menos à inflação, assim, priorizam o pleno emprego e apresentam uma política econômica expansionista. Já partidos de direita (conservadores) são mais avessos à inflação e menos ao desemprego, portanto, priorizam a estabilidade de preços e o equilíbrio no balanço de pagamentos, adotando políticas econômicas mais contracionistas.

Os modelos Racionais, que surgem nas décadas de 70 e 80 , diferem-se dos demais por considerarem que os agentes formam suas expectativas de forma racional e não de forma adaptativa. Sendo assim, os policy-makers continuam fazendo suas escolhas por oportunismo, enfoque clássico, ou por ideologia, enfoque partidário, no entanto, os eleitores passam a formular suas expectativas não apenas baseando-as em informações passadas e presentes (expectativas adaptativas), mas também antecipando ações e decisões do governo no longo prazo (ajustamento das expectativas). Dessa forma, a adoção de políticas econômicas se torna ineficaz em relação a impactos reais na economia, o que torna mais provável a existência de ciclos de curto em detrimento dos de longo prazo, uma vez que no curto prazo os agentes racionais estão mais sujeitos à assimetria de informações.

Como exemplo pode-se citar Santa-Clara e Valkanov (2003, pág. 1.841), que testam se há diferenças significativas no risco e retorno de ações e portfólios devido a frente partidária no poder Republicanos ou Democratas. O período analisado, de 1927 a 1998, compreende 18 eleições presidenciais e 864 observações mensais. Foram utilizadas análises de regressões com variáveis de controle (como o log da relação preço dividendo - DPt) e duas variáveis dummy, uma assumindo o valor de 1 para Republicanos no poder e 0 para demais e outra assumindo o valor de 1 para Democratas e 0 para demais. Foram encontradas evidências de que os retornos reais são maiores nos mandatos dos Democratas que nos dos Republicanos. Entretanto, não foram encontradas diferenças significativas no grau de risco devido à frente partidária no poder.

Worthington (2006, pág. 3) analisou a influência de ciclos políticos no mercado de ações da Austrália entre 1958 e 2005, com uma amostra com doze mil e sessenta e sete observações referentes às cotações de fechamento de ações selecionadas. O início e o fim dos mandatos de primeiro ministro foram usados como critério para formação de subamostras, o que permite a comparação do desempenho do mercado entre períodos com ministros diferentes no poder.

Outras subamostras foram formadas agrupando-se as observações de acordo com a frente partidária que estava no poder, o que possibilitou testar os ciclos políticos segundo o enfoque partidário. É relevante destacar que dois grupos dominam o espectro político australiano ao nível federal: a Coligação - aliança de centro-direita - e o Partido Trabalhista Australiano - partido de centro-esquerda.

Por meio de testes de Wald foram comparados os retornos e as volatilidades das ações entre períodos com a Coligação no poder e períodos com o Partido Trabalhista no poder. Para os retornos, 
a hipótese de igualdade dos coeficientes não é rejeitada, já para as volatilidades ela é rejeitada. Assim, há indícios de que a ideologia do partido não influenciou significativamente o retorno do mercado, porém, influenciou positivamente as volatilidades durante os governos trabalhistas.

Tal resultado leva a alguns questionamentos relevantes: Onde estaria a exigência de prêmios de risco pelos investidores, uma vez que os retornos foram estatisticamente iguais? Ineficiências de mercado podem realmente explicar tal fato? (essa é uma das suposições do autor).

\section{METODOLOGIA}

Conforme visto, há fundamentos teóricos e evidências empíricas a respeito da influência das manipulações eleitorais sobre as flutuações econômicas. Para testar tal hipótese, esse estudo analisou as possíveis alterações no risco e no retorno dos ativos devido à influência do calendário eleitoral, neste caso, uma decomposição com dummies. Tal análise foi baseada na interpretação de modelos econométricos estimados através do método dos Mínimos Quadrados Ordinários (MQO), conforme pode ser visto em Worthington (2006, pág. 8) e demonstrado em Gujarati e Porter (2011, pag. 850). Foram especificados dois modelos, um para testar a influência sobre retornos e outro a influência sobre os riscos:

$$
\begin{aligned}
& R_{t}=\beta_{1} \text { Presd }+\beta_{2} \text { Tend }_{t}+\beta_{3} \text { Stend }_{t}+\beta_{4} \text { PRE }_{t}+\beta_{5} \text { POS }_{t}+\varepsilon_{t} \\
& V_{t}=\beta_{1} \operatorname{Pr} \text { esd } \\
& t
\end{aligned}
$$

Em que:

$R_{t}=$ retorno nominal ou real

$V_{t}=$ volatilidade nominal ou real

$\operatorname{Pr} e s d_{t}=$ variáveis dummy para captar reações do mercado ao presidente no poder

Tend $_{t}$ e Stend ${ }_{t}=$ tendência de tempo linear e quadrática, respectivamente

$P R E_{t}=$ variável dummy para captar influência pré-eleitoral

$P O S_{t}=$ variável dummy para captar influência pós-eleitoral

$\mathcal{E}_{t}=$ termo de erro

A série do retorno diário $\left(R_{t}\right)$, variável dependente do modelo, foi calculada da seguinte maneira: $R_{t}=100 \ln \left(P_{t} / P_{t-1}\right)$, em que $P_{t}$ é a cotação no dia e $P_{t-1}$ é a cotação no dia anterior. Obtiveram-se assim, os retornos nominais e reais diários dos ativos estudados, sendo que para o cálculo daquele utilizou-se as cotações de fechamento nominais e para o cálculo destes utilizou-se as cotações de fechamento deflacionadas pelo IGPM. As cotações foram obtidas no banco de dados 
Economática ®. Foram utilizados os dados de fechamento das ações e do lbovespa ajustados aos proventos.

A série da volatilidade diária dos retornos $\left(V_{t}\right)$, variável que representa o risco dos ativos em estudo, foi mensurada através do desvio padrão dos retornos dos ativos. Por exemplo, a volatilidade de um determinado dia $t$ foi dada como o desvio-padrão dos retornos de uma janela de vinte e dois dias de negociações, ou seja, a volatilidade do dia t foi expressa pelo desvio padrão do período que compreende o retorno do dia $t$ e dos vinte e um dias anteriores a t. Embora não haja na literatura financeira uma maneira consagrada de se calcular a volatilidade diária de um ativo, optou-se por calcular da mesma forma que Worthington (2006, pág. 8).

Tanto as séries do retorno quanto as da volatilidade, foram submetidas ao teste de raiz unitária Augmented Dickey-Fuller (ADF), conforme indicam Gujarati e Porter (2011, pag. 751). Os resultados indicaram a rejeição da hipótese nula de raiz unitária, o que evidencia a estacionariedade das séries e a qualificação das mesmas para modelagem econométrica.

O período escolhido para estudo, entre 1995 e 2010, compreende três eleições presidenciais -4 de outubro de 1998, 6/27 ( $1^{\circ}$ e $2^{\circ}$ Turnos) de Outubro de 2002 e $1 / 29$ ( $1^{\circ}$ e $2^{\circ}$ Turnos) de Outubro de 2006 - e quatro mandatos presidenciais; dois de Fernando Henrique Cardoso (1995/1998) e dois de Luiz Inácio Lula da Silva (2002/2006), conforme (BRASIL, 2012).

A estrutura política brasileira não tem duas frentes partidárias bem definidas como o caso dos EUA, Austrália ou Nova Zelândia, o que impossibilitou a inserção ao modelo de uma dummy que as representasse. Porém, como o período em estudo compreende o mandato de apenas dois presidentes, foi possível verificar se o mercado de ações reagiu de maneiras distintas de acordo com o presidente que estava no poder. Para testar essa hipótese foi especificada a seguinte variável dummy: Presd $d_{t}$ - que assume o valor de 1 para todos os dias dos mandatos do presidente Fernando Henrique Cardoso e 0 para todos os dias dos mandatos do presidente Luiz Inácio Lula da Silva.

Assim como em Worthington (2006, pág. 8), foram incluídas no modelo duas tendências de tempo: a variável Tend $_{t}$ - que é uma tendência linear que assume o valor de um para o primeiro dia do mandato do presidente, dois para o segundo dia e assim por diante a cada dia de negociação - e a variável Stend $t_{t}$ - que é o quadrado da variável Tend $_{t}$, incluída para captar possíveis relações não lineares. Essas tendências buscam captar uma possível relação de crescimento, linear ou não ( Tend $_{t}$ e Stend $_{t}$ ), das variáveis dependentes do modelo ao longo dos mandatos presidenciais. Ou seja, torna-se possível analisar, através da reação do mercado, se os governos mantêm políticas estáveis ao longo dos mandatos ou se apresentam políticas oportunistas com fins eleitoreiros.

Com o intuito de testar a reação do mercado devido à formação de expectativas em relação às eleições, foram incluídas quatro dummies ao modelo - duas mensais e duas semanais. As dummies mensais são - Pre 1; que assumem o valor de 1 para cada dia dos meses que antecedem às eleições e 0 para os demais dias e Pos 1; que assumem o valor de 1 para cada dia dos meses que sucedem às eleições e 0 para os demais. As dummies semanais são - Pre 2; que assumem o valor 
de 1 para cada dia das semanas que antecedem às eleições e 0 para os demais dias e Pos 2; que assumem o valor de 1 para cada dia das semanas que sucedem às eleições e 0 para os demais.

Em contraposição às tendências de tempo que testam a existência de crescimento do risco e do retorno ao longo dos mandatos, as dummies testam a hipótese de que o risco e o retorno são afetados nas semanas e meses próximos às eleições, dito de outra maneira, as dummies testam se o mercado forma expectativas e reage às eleições de maneira imediata e não gradativa.

Foram selecionados para estudo o índice IBOVESPA e as ações preferenciais PETROBRAS PN (PETR4) e ELETROBRAS PNB (ELET6). O primeiro foi escolhido por ser a proxy da carteira representativa do mercado de ações brasileiro e os outros dois por possuírem o Estado (União Federal) como acionista majoritário, e apresentarem boa liquidez, participação no mercado e volume. A justificativa em se escolher também papéis de estatais, e não só um índice representativo do mercado, está no fato de que os investidores donos desses ativos podem apresentar expectativas e reações diferentes do mercado em relação às políticas oportunistas e resultados das eleições.

Tabela 1 - Teste da influência dos ciclos políticos sobre o mercado (lbovespa)

\begin{tabular}{|c|c|c|c|c|c|c|c|c|c|}
\hline \multicolumn{9}{|c|}{ Variáveis } & Real \\
\hline $\begin{array}{c}\text { Variáveis } \\
\text { independentes }\end{array}$ & dependentes & 1 mês & 1 semana & 1 mês & 1 semana & 1 mês & 1 semana & 1 mês & 1 semana \\
\hline \multirow[t]{2}{*}{ Presd } & Coeficientes & $-0,0112$ & $-0,0088$ & 1,0328 & 1,0518 & $-0,0339$ & $-0,0316$ & 1,0423 & 1,0613 \\
\hline & p-valor & 0,8831 & 0,9085 & $0,0000^{\star * *}$ & $0,0000^{* * *}$ & 0,6567 & 0,6786 & $0,0000^{* * *}$ & $0,0000^{* * *}$ \\
\hline \multirow[t]{2}{*}{ Tend } & Coeficientes & 0,0006 & 0,0006 & 0,0059 & 0,0057 & 0,0005 & 0,0005 & 0,0059 & 0,0057 \\
\hline & p-valor & $0,0565^{*}$ & $0,0637^{*}$ & $0,0000^{* * *}$ & $0,0000^{\star * *}$ & $0,0972^{*}$ & 0,1078 & $0,0000^{* * *}$ & $0,0000^{* * *}$ \\
\hline \multirow[t]{2}{*}{ Stend } & Coeficientes & 0,0000 & 0,0000 & 0,0000 & 0,0000 & 0,0000 & 0,0000 & 0,0000 & 0,0000 \\
\hline & p-valor & $0,0595^{*}$ & $0,0656^{*}$ & $0,0000^{\star * *}$ & $0,0000^{* * *}$ & $0,0903^{*}$ & $0,0983^{*}$ & $0,0000^{* * *}$ & $0,0000^{* * *}$ \\
\hline \multirow[t]{2}{*}{ Dummy Pre 1} & Coeficientes & $-0,1758$ & - & 1,4021 & - & $-0,1665$ & - & 1,4101 & - \\
\hline & p-valor & 0,6676 & - & $0,0890^{*}$ & - & 0,6866 & - & $0,0857^{*}$ & - \\
\hline \multirow[t]{2}{*}{ Dummy Pos 1} & Coeficientes & 0,6275 & - & 0,6861 & - & 0,5916 & - & 0,6915 & - \\
\hline & $p$-valor & $0,0157^{* *}$ & - & $0,0499^{* *}$ & - & $0,0236^{* *}$ & - & $0,0478^{\star *}$ & - \\
\hline \multirow[t]{2}{*}{ Dummy Pre 2} & Coeficientes & - & 0,8246 & - & 1,2776 & - & 0,8145 & - & 1,2909 \\
\hline & p-valor & - & $0,0887^{*}$ & - & 0,1418 & - & 0,0854 * & - & 0,1360 \\
\hline \multirow[t]{5}{*}{ Dummy Pos 2} & Coeficientes & - & 0,3214 & - & 1,4232 & - & 0,2719 & - & 1,4347 \\
\hline & $p$-valor & - & 0,3527 & - & 0,1048 & - & 0,4194 & - & 0,1010 \\
\hline & Estatística F & 2,1531 & 1,7158 & 217,4963 & 211,8811 & 1,4960 & 1,2259 & 218,0479 & 212,4132 \\
\hline & p-valor & $0,0565^{*}$ & 0,1274 & $0,0000^{* * *}$ & $0,0000^{* * *}$ & 0,1876 & 0,2940 & $0,0000^{* * *}$ & $0,0000^{* * *}$ \\
\hline & $N^{0}$ obs & 3958 & 3958 & 3958 & 3958 & 3958 & 3958 & 3958 & 3958 \\
\hline
\end{tabular}

Fonte: Elaborada pelo autor

Notas: Todos os p-valores incorporam a correção de Newey West para heterocedasticidade e autocorrelação.

$\left.{ }^{*}\right)\left({ }^{* *}\right)\left({ }^{* *}\right)$ para níveis de significância de $10 \%, 5 \%$ e 1\%, respectivamente.

\section{RESULTADOS}

O emprego da metodologia proposta para testar a existência de Ciclo para o lbovespa apresenta evidências de que os retornos tanto nominais quanto reais não são influenciados pelo presidente que está no poder, pois em todos os modelos os coeficientes das dummies Presd não foram estatisticamente significativos. 
A tendência linear foi positiva e estatisticamente diferente de zero ao nível de significância de $10 \%$ em ambos os modelos para o retorno nominal, porém o coeficiente estimado foi muito pequeno, o que indica um leve crescimento dos retornos nominais durante ambos os mandatos. Para o retorno real o resultado é o mesmo. No entanto, apenas o modelo com dummy semanal foi estatisticamente positivo e significativo a $10 \%$. A variável tendência ao quadrado, Stend, apresentou valores próximos de zero apesar de ser estatisticamente significativa em todos os modelos.

As dummies Pre 1 não são estatisticamente significativas para nenhum dos dois retornos, todavia as dummies Pos 1 são positivas e significativas ao nível de 5\% para ambos retornos. Tais resultados levantam indícios de que os retornos não são influenciados no mês anterior às eleições, mas são influenciados positivamente no mês posterior às eleições.

As dummies Pre 2 são positivas e estatisticamente diferentes de zero ao nível de significância de 10\% para retornos nominais e reais, porém as dummies Pos 2 são estatisticamente iguais a zero. Esses resultados sugerem que os retornos crescem na semana anterior às eleições, mas não são influenciados na semana posterior às eleições.

Em relação à volatilidade os resultados são um pouco diferentes. As dummies Presd são positivas e significativas a $1 \%$ nos modelos semanais e mensais tanto para as volatilidades nominais quanto para as reais, sendo que os coeficientes estimados são maiores para as volatilidades reais e para os modelos semanais. Este resultado aponta para o fato de que durante o governo $\mathrm{FHC} \circ$ mercado apresentou risco mais elevado em comparação ao governo Lula.

As tendências, assim como no caso dos retornos, foram positivas com baixos valores para os coeficientes, e estatisticamente diferentes de zero ao nível de significância de $1 \%$ em ambos os modelos, o que aponta para um leve aumento da volatilidade durante os mandatos analisados. Novamente a variável Stend foi significativa, mas com valores próximos de zero em todos os modelos.

As dummies Pre 1 e Pos 1 foram positivas e significativas para as duas volatilidades, porém a primeira ao nível de $10 \%$ e a segunda ao nível de $5 \%$. Isso levanta evidências de que a volatilidade dos retornos aumenta no mês anterior e no posterior às eleições, sendo que o aumento é maior no mês anterior.

As dummies Pre 2 e Pos 2 não foram estatisticamente significativas, assim como em Worthington (2006, pág. 12), o que indica que as volatilidades não foram afetadas nas semanas imediatamente anteriores e posteriores às eleições.

Quanto às estatais, os resultados para Petr4 encontram-se a seguir. 
Tabela 2 - Teste da influência dos ciclos políticos sobre a Petr4

\begin{tabular}{|c|c|c|c|c|c|c|c|c|c|}
\hline & $\begin{array}{c}\text { Variáveis } \\
\text { dependentes }\end{array}$ & Retor & ominal & Volatilid & Nominal & & Real & Volatilid & e Real \\
\hline independentes & & 1 mês & 1 semana & 1 mês & 1 semana & 1 mês & 1 semana & 1 mês & 1 semana \\
\hline Presd & Coeficientes & 0,0170 & 0,0163 & 1,2417 & 1,2635 & $-0,0057$ & $-0,0065$ & 1,2434 & 1,2653 \\
\hline & p-valor & 0,8627 & 0,8668 & $0,0000^{* * *}$ & $0,0000^{\star \star *}$ & 0,9532 & 0,9464 & $0,0000^{* * *}$ & $0,0000^{\star \star \star}$ \\
\hline Tend & Coeficientes & 0,0008 & 0,0008 & 0,0071 & 0,0069 & 0,0007 & 0,0008 & 0,0072 & 0,0070 \\
\hline & p-valor & $0,0379^{* *}$ & $0,0292^{* *}$ & $0,0000^{\star \star *}$ & $0,0000^{\star * *}$ & $0,0589^{\star}$ & $0,0465^{* *}$ & $0,0000^{* \star *}$ & $0,0000^{* * *}$ \\
\hline Stend & Coeficientes & 0,0000 & 0,0000 & 0,0000 & 0,0000 & 0,0000 & 0,0000 & 0,0000 & 0,0000 \\
\hline & $p$-valor & $0,0390^{* *}$ & $0,0258^{* *}$ & $0,0000^{* * *}$ & $0,0000^{* * *}$ & $0,0543^{*}$ & $0,0370^{* *}$ & $0,0000^{* * *}$ & $0,0000^{* * *}$ \\
\hline Dummy Pre 1 & Coeficientes & $-0,2323$ & - & 1,7235 & - & $-0,2229$ & - & 1,7291 & - \\
\hline & $p$-valor & 0,6285 & - & $0,0988^{*}$ & - & 0,6452 & - & $0,0976^{*}$ & - \\
\hline Dummy Pos 1 & Coeficientes & 0,5816 & - & 0,9750 & - & 0,5458 & - & 0,9782 & - \\
\hline & $p$-valor & 0,1227 & - & $0,0181^{* *}$ & - & 0,1510 & - & $0,0182^{* *}$ & - \\
\hline Dummy Pre 2 & Coeficientes & - & 1,3077 & - & 2,0479 & - & 1,2977 & - & 2,0477 \\
\hline & $p$-valor & - & $0,0257^{\star *}$ & - & $0,0393^{* *}$ & - & $0,0220^{* *}$ & - & $0,0394^{* *}$ \\
\hline Dummy Pos 2 & Coeficientes & - & 0,1625 & - & 2,0651 & - & 0,1131 & - & 2,0660 \\
\hline & $p$-valor & - & 0,7449 & - & $0,0393^{* *}$ & - & 0,8161 & - & $0,0394^{* *}$ \\
\hline & Estatística F & 2,2345 & 2,7263 & 211,7153 & 202,8280 & 1,6084 & 2,1916 & 212,2123 & 203,4548 \\
\hline & p-valor & $0,0483^{* *}$ & $0,0183^{* *}$ & $0,0000^{\star * *}$ & $0,0000^{\star \star *}$ & 0,1542 & $0,0524^{*}$ & $0,0000^{* * *}$ & $0,0000^{\star \star \star}$ \\
\hline & $N^{0}$ obs & 3.954 & 3.954 & 3.954 & 3.954 & 3.954 & 3.954 & 3.954 & 3.954 \\
\hline
\end{tabular}

Fonte: Elaborada pelo autor

Notas: Todos os p-valores incorporam a correção de Newey West para heterocedasticidade e autocorrelação

$\left({ }^{*}\right)\left(^{* *}\right)\left(^{* * *}\right)$ para níveis de significância de $10 \%, 5 \%$ e $1 \%$, respectivamente.

Assim como o resultado obtido para o mercado, não há evidências a respeito da influência do indivíduo no poder sobre os retornos da Petr4, pois em nenhum dos modelos estimados para os retornos os coeficientes para as dummies Presd foram estatisticamente significativos.

As tendências foram positivas e estatisticamente diferentes de zero ao nível de significância de $5 \%$ em ambos os modelos para retornos nominais e reais, mas assim como ocorreu no modelo de mercado, o crescimento apresentado pelos retornos foi muito suave, uma vez que os coeficientes estimados foram pequenos. Novamente as variáveis tendências ao quadrado apresentaram valores significativos, porém próximos de zero.

As dummies Pre 1 e Pos 1 não apresentaram coeficientes estimados significativos para nenhum dos dois retornos, diferentemente do modelo de mercado que apresentou dummies Pos 1 significativas. Sendo assim, não temos indícios de que o calendário eleitoral afeta os retornos da Petr4 no mês que antecede nem no que sucede às eleições.

As dummies Pre 2 foram positivas e estatisticamente diferentes de zero ao nível de significância de 5\% para retornos nominais e reais. Contudo, as dummies Pos 2 não foram significativas. Esses resultados apontam que assim como o mercado, os retornos da Petr4 cresceram na semana anterior às eleições, mas não foram influenciados na semana posterior às eleições. Vale ressaltar que esse crescimento se dá em uma proporção maior que o apresentado pelo mercado. 
Para o risco, as dummies Presd foram positivas e estatisticamente diferentes de zero a $1 \%$ de significância, sendo que os coeficientes estimados para as volatilidades reais foram maiores que os estimados para as nominais. Este resultado levanta evidências que a volatilidade dos retornos da Petr4 foram maiores no governo FHC que no governo Lula, sendo que tal volatilidade foi ainda maior que a apresentada pelo mercado, uma vez que os coeficientes estimados foram maiores que os encontrados para o lbovespa.

As variáveis Tend, estimadas para as volatilidades reais e nominais, foram positivas, significativas a $1 \%$ e apresentarem valores maiores que estimados para os modelos dos retornos $\mathrm{e}$ também maiores que os estimados para o Ibovespa. Portanto, o ativo Petr4 teve um leve aumento da volatilidade ao longo dos anos, esse que se deu em proporção maior que o ocorrido no mercado. $O$ coeficiente de Stend, embora significativo, é praticamente igual a zero.

As dummies Pre 1 foram estatisticamente significativas ao nível de $10 \%$, as Pos 1 ao nível de $5 \%$ e os coeficientes estimados foram positivos e maiores que os obtidos para o Ibovespa. Assim, temos indícios de que a volatilidade dos retornos aumentou no mês anterior e no posterior às eleições. Além disso, tal aumento ocorreu em proporção maior que no mercado.

Em oposição ao resultado exibido pelo Ibovespa e também por Worthington (2006, pág. 10) em relação às dummies semanais, as dummies Pre 2 e Pos 2 foram estatisticamente significativas ao nível de 5\% e apresentaram coeficientes estimados maiores que as dummies Pre e Pos 1. Dessa maneira, há evidências de que as volatilidades dos retornos do ativo Petr4 cresceram substancialmente nas semanas imediatamente anteriores e posteriores às eleições, o que aponta uma formação de expectativas mais imediata em relação aos ativos de estatais em contraposição ao que ocorre no mercado.

No que diz respeito à Elet6, as dummies Presd foram estatisticamente iguais a zero para os modelos dos retornos, dessa maneira as evidências não apontam influência do presidente no poder sobre os retornos do ativo Elet6. Esse resultado foi o mesmo encontrado para o lbovespa e Petr4. 
Tabela 3 - Teste da influência dos ciclos políticos sobre a Elet6

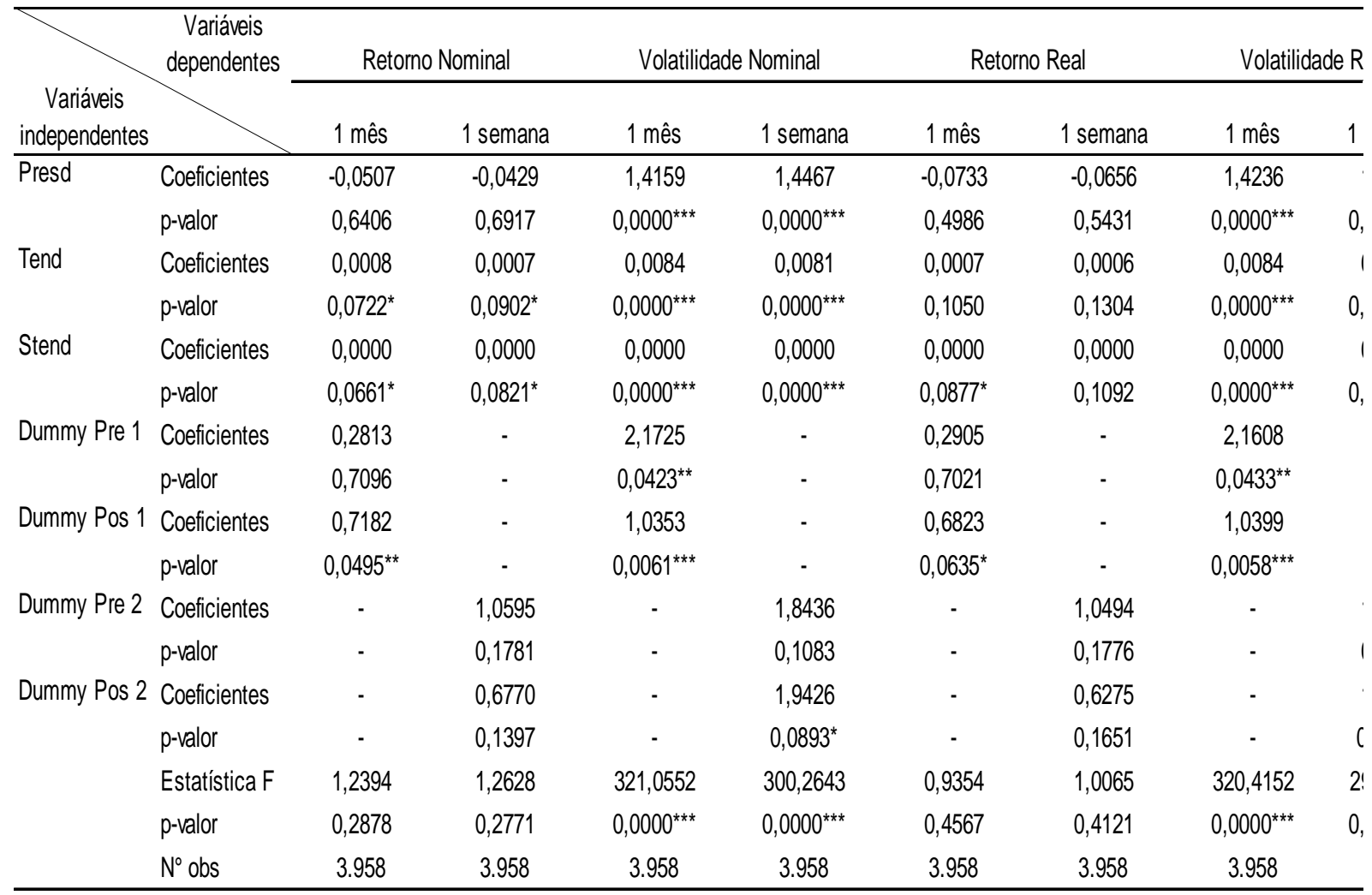

Fonte: Elaborada pelo autor

Notas: Todos os p-valores incorporam a correção de Newey West para heterocedasticidade e autocorrelação

$\left({ }^{*}\right)\left(^{* *}\right)\left(^{* * *}\right)$ para níveis de significância de $10 \%, 5 \%$ e $1 \%$, respectivamente.

As tendências foram positivas e significativas a $10 \%$ para os retornos nominais e não significativas para os retornos reais. Assim, há evidências para um leve crescimento apenas do retorno nominal ao longo dos anos, resultado distinto do encontrado para o lbovespa e para a Petr4 os quais apresentaram tal crescimento também para seus retornos reais. As variáveis Stend foram nulas e significativas para todos os modelos, exceto para o modelo semanal do retorno real no qual o coeficiente não foi significativo.

As dummies Pre 1 não são estatisticamente significativas em nenhum dos modelos para os retornos. No entanto, as dummies Pos 1 são positivas e estatisticamente significativas ao nível de $5 \%$ para ambos os retornos. Tal resultado é semelhante ao encontrado para o mercado, no qual não há evidências para influência do calendário eleitoral sobre os retornos no mês anterior às eleições, mas há no mês posterior.

As dummies Pre 2 e Pos 2 foram estatisticamente iguais a zero para retornos nominais e reais. Assim, a ação da Eletrobrás não mostrou indícios de que seu retorno foi afetado na semana anterior e na posterior às eleições, diferentemente do lbovespa.

Em relação à volatilidade dos retornos, as dummies Presd foram positivas e estatisticamente significativas a $1 \%$, o que aponta para uma maior volatilidade dos retornos durante o governo $\mathrm{FHC}$ em relação ao governo Lula. Há evidências de que a volatilidade da Elet6 foi a mais sensível em 
relação ao presidente no poder, uma vez que os coeficientes estimados foram maiores que os obtidos para o ativo Petr4 e para o lbovespa.

As variáveis Tend foram positivas e significativas a $1 \%$ tanto para o modelo com volatilidades nominais quanto para o com volatilidades reais, o que indica crescimento da volatilidade dos retornos da Elet6 ao longo do período em estudo. Novamente os coeficientes estimados foram maiores que os encontrados para o mercado e para o ativo da Petrobrás.

As dummies Pre 1 foram estatisticamente significativas ao nível de $5 \%$ e as Pos 1 ao nível de $1 \%$. Os coeficientes estimados foram positivos e maiores que os apresentados pelo mercado e pela Petr4, sendo que os das dummies Pre foram maiores que os das dummies Pos. Dessa forma, há evidências de que a volatilidade dos retornos aumenta no mês anterior e no posterior às eleições, isso em uma proporção maior nos mês anterior às eleições.

As dummies Pre 2 não foram estatisticamente significativas, ao passo que as dummies Pos 2 foram significativas a $10 \%$ e apresentaram coeficientes estimados positivos. Sendo assim, há evidências de que a volatilidade apresentada pela Elet6 não foi afetada na semana anterior mais cresceu na posterior às eleições.

\section{CONCLUSÕES}

As evidências empíricas apresentadas rejeitam a hipótese de que os retornos do mercado, representados pelo lbovespa, e dos papéis de estatais, no caso Petr4 e Elet6, são influenciados pelo indivíduo no poder, ou seja, os retornos não mudaram (estatisticamente) pelo fato do país ser comandado por FHC ou por Lula. Entretanto, o oposto ocorre no caso do risco (volatilidade), pois há evidências de que durante o governo FHC os ativos em estudo apresentaram maior volatilidade em relação ao observado durante o governo Lula, sendo as volatilidades reais sempre maiores que as nominais.

Esses resultados apontam para uma pergunta em trabalhos futuros: dada a relação positiva esperada entre a volatilidade e o prêmio de risco esperado, que motivo levou o mercado a não exigir tal compensação pelo risco? Dito de outra forma, por que não há evidências de que o retorno fora mais elevado durante o governo FHC dado que a volatilidade o foi?

Os resultados sugerem, de forma geral, que nos meses e semanas próximos às eleições há um crescimento brusco dos retornos e volatilidades em contraposição a evidência de que esses apresentam um crescimento muito suave ao longo dos mandatos presidenciais. Uma explicação para este fato é que o mercado reage ao resultado, ou provável resultado, das eleições de maneira imediata e não de forma gradativa ao longo dos mandatos. Essa consequente formação imediata de expectativas pode ser um indício de que as políticas econômicas adotadas durante o decorrer dos mandatos não são as mesmas que as adotadas no início ou no final dos mesmos, ou seja, o governo modifica as políticas econômicas em função do calendário eleitoral (hipótese dos ciclos políticos) e o mercado percebe e reage a estas manipulações oportunistas.

Outro resultado importante é que não é possível rejeitar a hipótese de que os ativos das estatais, nesse estudo representados por Petr4 e Elet6, reagem de forma distinta do mercado em 
relação ao calendário eleitoral. Tais ativos sempre apresentaram um crescimento maior dos seus retornos e volatilidades em comparação com o resultado de mercado em todos os modelos nos períodos pré e pós eleição. Isso pode ser uma evidência de que uma empresa controlada pela União Federal tem seus ativos mais sensíveis às influências geradas pelas variáveis políticas dos modelos calendário eleitoral e presidente no poder.

São necessários mais estudos sobre ciclos político-econômicos no mercado de ações brasileiro, mas as evidências obtidas neste estudo apontam para uma influência de políticas oportunistas no risco e o retorno do mercado brasileiro de ações.

Estudos do CEPE [ISSN 1982-6729]. Santa Cruz do Sul, n. 44, p.39-51, jul./dez. 2016.

https://online.unisc.br/seer/index.php/cepe/index 


\section{REFERÊNCIAS}

DOWNS, Anthony. An Economy Theory of Democracy. New York: Harper and Row, 1957.

DRAZEN, Allan. Political Economy in Macroeconomics. Princeton, Princeton University Press, 2001. 792p.

FAMA, E. Efficient capital markets: a review of theory and empirical works. The Journal of Finance, v. 25, n. 2, 1970.

FIALHO, Tânia M. M. Ciclos Políticos: uma Resenha. Revista de Economia Política, v. 19, n. 2 (74), p. 131-148, Abr./Jun. 1999.

GUJARATI, D. N.; PORTER, D. C. Econometria básica. 5르 Ed. Porto Alegre: AMGB, 2011.

NORDHAUS, William D. The Political Business Cycle. Review of Economic Studies, v. 42, p. 169190, 1975.

SANTA-CLARA, Pedro; VALKANOV, Rossen. The Presidential Puzzle: Political Cycles and the Stock Market. The journal of Finance, v. 58(5), p. 1841 - 1872, Out. 2003.

SNOWDON, Brian \& VANE, Howard. Modern Macroeconomics: Its Origins, Development and Current State. Edward Elgar, 2005, 807p.

Tribunal Superior Eleitoral, Cronologia das eleições no Brasil (1945 - 2010). Disponível em: <http://www.tse.gov.br/internet/eleicoes/cronologia.htm>. Acesso em: 28 mar. 2012.

WORTHINGTON, Andrew C. Political cycles and risk and return in the Australian stock market, Menzies to Howard. School of Accounting and Finance Working Paper Series, n. 6, 2006.

Disponível em: <http://ro.uow.edu.au/cgi/viewcontent.cgi?article=1210\&context=commpapers > . Acesso em: 01 set. 2010. 